\section{JURNAL EKONOMI EFEKTIF}

ISSN : $2622-8882$, E-ISSN : 2622-9935

Jurnal Ekonomi Efektif, Vol. 4, No. 2, Januari 2022 @Prodi Manajemen Fakultas Ekonomi

Universitas Pamulang

\title{
PENGARUH DISIPLIN TERHADAP PRODUKTIVITAS KARYAWAN PADA PT ASURANSI BINTANG DI JAKARTA
}

\author{
Eko Yulianto ${ }^{1}$, Hamsinah $^{2 *}$ \\ Universitas Pamulang, Tangerang Selatan, Banten, Indonesia \\ ekoy93@gmail.com ${ }^{1}, \underline{\text { dosen00941@unpam.ac.id }{ }^{2 *}}$ \\ Manuskrip: Oktober -2021; Ditinjau: November: -2021; Diterima: Desember-2021; Online: Januari -2022; \\ Diterbitkan: Januari-2022
}

\begin{abstract}
ABSTRAK
Penelitian ini bertujuan untuk mengetahui pengaruh disiplin terhadap produktivitas karyawan pada PT. Asuransi Bintang di Jakarta. Metode yang digunakan adalah explanatory research dengan sampel sebanyak 70 responden. Teknik analisis menggunakan analisis statistik dengan pengujian regresi, korelasi, determinasi dan uji hipotesis. Hasil penelitian ini variabel disiplin diperoleh nilai rata-rata skor sebesar 3,794 dengan kriteria baik. Variabel produktivitas karyawan diperoleh nilai rata-rata skor sebesar 3,874 dengan kriteria baik. Disiplin berpengaruh positif dan signifikan terhadap produktivitas karyawan dengan nilai persamaan regresi $\mathrm{Y}=13,247+0,672 \mathrm{X}$, dan nilai koefisien korelasi 0,785 atau memiliki tingkat hubungan yang kuat dengan nilai determinasi $61,7 \%$. Uji hipotesis diperoleh signifikansi $0,000<0,05$.
\end{abstract}

\section{Kata Kunci: Disiplin, Produktivitas Karyawan}

\begin{abstract}
This study aims to determine the effect of discipline on employee productivity at PT. Star Insurance in Jakarta. The method used is explanatory research with a sample of 70 respondents. The analysis technique uses statistical analysis with regression, correlation, determination and hypothesis testing. The results of this study of the discipline variable obtained an average score of 3.794 with good criteria. Employee productivity variable obtained an average score of 3.874 with good criteria. Discipline has a positive and significant effect on employee productivity with the value of the regression equation $Y=13.247+0.672 X$, and the correlation coefficient value of 0.785 or has a strong relationship with a determination value of $61.7 \%$. Hypothesis testing obtained a significance of $0.000<0.05$.
\end{abstract}

Keywords: Discipline, Employee Productivity 


\section{PENDAHULUAN}

\section{A. Latar Belakang}

Perusahaan merupakan suatu organisasi yang mempunyai berbagai macam tujuan. Aktivitas suatu perusahaan dalam pencapaian tujuan tersebut diperlukan pengelolaan faktor-faktor produksi yang terdiri dari sumber daya alam, sumber daya manusia, modal, bahan baku, mesin, teknologi. Perusahaan harus selalu memperhatikan keterkaitan antara faktor-faktor produksi tersebut, dengan demikian perusahaan dituntut untuk dapat mengelola dengan sebaik-baiknya terutama dalam bidang sumber daya manusia sehingga mampu bekerja lebih efektif dan efisien. Suatu organisasi dapat berjalan efektif apabila fungsi-fungsi manajemen seperti perencanaan (planning), pengorganisasian (organizing), pengarahan (actuating) dan pengendalian (controlling) apabila semua itu berfungsi dengan baik, serta unsur-unsur penunjangnya tersedia dan memenuhi persyaratan.

Pentingnya sumber daya manusia ini perlu disadari oleh semua tingkatan manajemen di perusahaan. Sumber daya manusia merupakan suatu organisasi karena sumber daya memiliki bakat, tenaga dan kreativitas yang sangat dibutuhkan oleh perusahaan untuk mencapai tujuannya. Majunya teknologi, berkembangnya informasi, tersedianya modal dan memadai bahan, namun jika tanpa sumber daya manusia, maka akan sulit bagi organisasi untuk mencapai tujuan tersebut.

Salah satu produk jasa terkemuka dalam bidang asuransi adalah asuransi jiwa, dimana asuransi jiwa merupakan salah satu hal yang sangat penting karena sebagai salah satu instrumen yang dapat digunakan untuk meminimalisasi resiko yang mungkin terjadi dalam kehidupan.

Perusahaan Asuransi saat ini sedang membangun bisnis yang sangat menjanjikan, terlebih sekarang masyarakat sudah mulai sadar dengan pentingnya asuransi. Masyarakat sekarang sudah mulai sadar dengan adanya asuransi jiwa, asuransi general itu memanglah sangat penting untuk kehidupan sekarang. Terlihat sekarang banyak sekali perusahaan-perusahaan asuransi yang berlomba mempromosikan produknya. Harga yang ditawarkan juga sangat menarik masyarakat agar menggunakan asuransi tersebut.

Bisnis asuransi saat ini memiliki pertumbuhan yang sangat baik. Namun dengan demikian, oleh karena semakin tinggi nya persaingan asuransi yang ada apabila perusahaan tersebut melakukan sedikit kesalahan pada harga, produk dan pelayanan terhadap masyarakan disini akan menyebabkan terjadinya kelambatan pada bisnis tersebut.

Betapa pun bagusnya tujuan dan rencana organisasi, merupakan langkah yang siasia jika unsur sumber daya manusianya tidak diperhatikan atau bahkan diterlantarkan. sebagaimana Hasibuan (2013:11) menyampaikan bahwa tujuan tidak mungkin terwujud tanpa peran aktif karyawan meskipun alat-alat yang dimiliki perusahaan begitu canggihnya" Oleh karena itu keberhasilan suatu perusahaan tidak hanya tergantung dengan teknologi perusahaan saja namun juga tergantung pada aspek sumber daya manusia yang dimiliki oleh perusahaan.

Faktor disiplin kerja sangat berperan penting dalam pelaksanaan kerja karyawan. Karena menurut Hasibuan (2013:193) adalah kesadaran dan kesediaan menaati semua peraturan perusahaan dan norma-norma sosial yang berlaku. Sedangkan menurut pendapat ahli yang lain, Rivai (2013:444) mengatakan bahwa disiplin kerja adalah suatu alat yang digunakan para manager untuk berkomunikasi dengan karyawan agar mereka bersedia untuk mengubah suatu perilaku, serta sebagai upaya meningkatkan kesadaran dan kesediaan seseorang mentaati semua peraturan perusahaan dan norma-norma sosial 
yang berlaku. Pada akhirnya pegawai yang mempunyai kedisiplinan kerja yang tinggi akan mempunyai kinerja yang baik karena waktu kerja dimanfaatkan sebaik mungkin untuk melaksankan pekerjaan sesuai dengan target yang ditetapkan. Karyawan wajib mendisiplinkan diri masing-masing mulai dari lingkungan yang paling kecil yaitu keluarga sampai lingkungan kerja agar tercipta produktivitas kerja karyawan yang baik dalam menjalani tugasnya sebagai karyawan.

PT. Asuransi Bintang Tbk menyadari pentingnya memiliki sumber daya manusia yang berkualitas dan memiliki komitmen serta menjaga kualitas yang konsisten untuk mampu mendorong kinerja organisasi yang membutuhkan daya dukung yang kuat dalam usaha mencapai misi dan misinya. Oleh sebab itu perusahaan sangat mengharapkan setiap karyawannya dapat menciptakan disiplin kerja yang tinggi demi kemajuan perusahaan dan pencapaian tujuan perusahaan yang efektif dan efisien. Akan tetapi hal ini tidak mudah apabila disiplin kerja karyawan masih rendah.

Salah satu tantangan yang dihadapi dalam meningkatkan produktivitas kerja karyawan adalah rendahnya tingkat kesadaran karyawan terhadap tugas dan tanggung jawab mereka dalam melaksanakan pekerjaan. Hal ini tercermin dalam berbagai hal, seperti karyawan yang tidak taat terhadap jam kerja serta karyawan yang tidak bersungguh-sungguh dalam melaksanakan tugas dan tanggung jawabnya dalam melaksanakan pekerjaan. Disiplin kerja yang baik adalah bukan atas dasar paksaan atau karena adanya punishment (peringatan) maupun reward (penghargaan) yang diberikan, akan tetapi berdasarkan kesadaran dari dalam diri karyawan masing-masing. Seperti yang terjadi pada karyawan di PT. Asuransi Bintang Tbk di Jakarta, berdasarkan hasil penelitian awal terlihat masih kurangnya disiplin kerja karyawan yang dilakukan baik oleh karyawan dinas dalam maupun karyawan dinas luar. Diantaranya banyak karyawan yang terlambat hadir dari jam kerja yang ditentukan dan karyawan yang tidak hadir tanpa memberikan keterangan. Persoalan seperti ini mencerminkan masih rendahnya tingkat kedisiplinan kerja karyawan, sehingga akan turut menurunkan produktivitas kerja.

Pencapaian keunggulan bersaing telah mengarah ke munculnya bidang yang dikenal sebagai sumber daya manusia untuk meningkatkan kinerja bisnis dan mengembangkan kultur organisasi yang mendorong inovasi dan peran penting atau implementasi yang berhasil dari sebuah rencana.

Keberhasilan suatu organisasi ditentukan oleh bertanggung jawabnya karyawan dalam melaksankan tugasnya dan tepat waktu pada saat masuk jam kantor, sedangkan dalam observasi yang telah dilakukan masih banyak karyawan yang menunda pelaksanaan tugas kantor,terlambat saat masuk jam kerja, keluar kantor pada saat jam jam kerja dan kurangnya komunikasi antar karyawan dengan pimpinan mempengaruhi produktivitas kerja karyawan pada masing-masing individu, karena produktivitas kerja karyawan sendiri dipengaruhi oleh karakteristik individu dan faktor lingkungan perusahaan, baik suasan kerja lingkungan fisik maupun leadership. Sedangkan para atasan sebagai motivator bagi para karyawan berusaha agar produktivitas kerja karyawan terus meningkat, perusahaan juga memberikan reward (bonus) yang sesuai dengan produktivitas kerja yg diberikan karayawan. Produktivitas kerja suatu keberhasilan individu dalam mengerjakan tugasnya yang bisa dilihat dari segi dimensi keterikatan, keahlian merencanakan, daya usaha dalam pekerjaan dan produktivitas kerja karyawan secara keseluruhan.

Dalam mencapai tujuannya PT. Asuransi Bintang Tbk memiliki beberapa untuk meningkatkan produktivitas diantaranya departemen Telemarketing, yaitu sistem pemasaran jarak jauh, dimana karyawan atau disebut juga Agen Telemarketing menghubungi customernya melalui telepon untuk melakukan penawaran produk 
asuransi. Namun hal ini belum dirasa optimal untuk menunjang produktivitas kinerja karyawan, karena departemen ini sering tidak mencapai target yang diberikan oleh perusahaan.

Berdasarkan latar belakang permasalahan diatas, maka penulis tertarik untuk melakukan penelitian lebih lanjut dengan judul: "Pengaruh Disiplin Kerja Terhadap Produktivitas Kerja Karyawan Pada PT. Asuransi Bintang Tbk di Jakarta".

\section{B. Rumusan Masalah}

a. Bagaimana disiplin pada PT. Asuransi Bintang di Jakarta ?.

b. Bagaimana produktivitas karyawan pada PT. Asuransi Bintang di Jakarta ?.

c. Adakah pengaruh antara disiplin terhadap produktivitas karyawan pada PT. Asuransi Bintang di Jakarta?.

\section{Tujuan Penelitian}

a. Untuk mengetahui kondisi disiplin pada PT. Asuransi Bintang di Jakarta.

b. Untuk mengetahui kondisi produktivitas karyawan pada PT. Asuransi Bintang di Jakarta.

c. Untuk mengetahui pengaruh disiplin terhadap produktivitas karyawan pada PT. Asuransi Bintang di Jakarta.

\section{TINJAUAN PUSTAKA}

\section{Disiplin}

Menurut Sutrisno (2016) mendefinisikan "Disiplin adalah perilaku seseorang yang sesuai dengan peraturan, prosedur kerja yang ada atau sikap dan tingkah laku serta perbuatan yang sesuai dengan peraturan dari organisasi baik tertulis maupun tidak tertulis". Dalam penelitian ini indikator yang digunakan meliputi: taat terhadap aturan waktu taat terhadap aturan organisasi, taat terhadap aturan perilaku dalam pekerjaan, taat terhadap peraturan lainnya.

\section{Produktivitas Karyawan}

Produktivitas merupakan cerminan kemampuan karyawan dalam melakukan pekerjaan dan hasil yang diperoleh berdasarkan sumber daya yang digunakan.Menurut Hasibuan dalam Busro (2018), produktivitas adalah perbandingan antara output (hasil) dengan input (masukan). Jika produktivitas naik akan meningkatkan efisiensi (waktubahan-tenaga) dan sistem kerja, teknik produksi dan adanya peningkatan keterampilan dari tenaga kerjanya.

\section{III.METODE PENELITIAN}

\section{Populasi}

Yang dijadikan sebagai populasi dalam penelitian ini adalah responden yang berjumlah 70 responden PT. Asuransi Bintang di Jakarta

\section{Sampel}

Teknik pengambilan sampling dalam penelitian ini adalah sampel jenuh, dimana semua anggota populasi dijadikan sebagai sampel. Dengan demikian sampel dalam penelitian ini sampel yang digunakan berjumlah 70 responden.

\section{Jenis Penelitian}

Jenis penelitian yang dipakai adalah asosiatif, dimana tujuannya adalah untuk mengetahui atau mencari keterhubungan antara variabel independen terhadap variabel dependennya. 


\section{Metode Analisis Data}

Dalam menganalisis data digunakan uji validitas, uji reliabilitas, analisis regresi linier sederhana, analisis koefisien korelasi, analisis koefisien determinasi dan pengujian hipotesis.

\section{IV.HASIL PENELITIAN}

\section{Analisis Deskriptif}

Pada pengujian ini digunakan untuk mengetahui skor minimum dan maksimum skor tertinggi, ratting score dan standar deviasi dari masing-masing variabel. Adapun hasilnya sebagai berikut:

Tabel 1. Hasil Analisis Descriptive Statistics

Descriptive Statistics

\begin{tabular}{l|r|r|r|r|r} 
& N & Minimum & Maximum & Mean & $\begin{array}{c}\text { Std. } \\
\text { Deviation }\end{array}$ \\
\hline Disiplin (X) & 70 & 27 & 49 & 37.94 & 4.527 \\
\hline Produktivitas Karyawan (Y) & 70 & 30 & 50 & 38.74 & 3.874 \\
\hline Valid N (listwise) & 70 & & & & \\
\hline Dising
\end{tabular}

Disiplin diperoleh varians minimum sebesar 27 dan varians maximum 49 dengan ratting score sebesar 3,794 dengan standar deviasi 4,527. Skor ini termasuk pada rentang sakala 3,40 - 4,19 dengan kriteria baik atau setuju. Produktivitas karyawan diperoleh varians minimum sebesar 30 dan varians maximum 50 dengan ratting score sebesar 3,874 dengan standar deviasi 3,874. Skor ini termasuk pada rentang sakala 3,40 $-4,19$ dengan kriteria baik atau setuju.

\section{Analisis Kuantitatif}

Pada analisis ini dimaksudkan untuk mengetahui pengaruh variabel independen terhadap variabel dependen. Adapun hasil pengujian sebagai berikut:

\section{a. Analisis Regresi Linier Sederhana}

Uji regresi ini dimaksudkan untuk mengetahui perubahan variabel dependen jika variabel independen mengalami perubahan. Adapun hasil pengujiannya sebagai berikut:

Tabel 2. Hasil Pengujian Regresi Linier Sederhana

$$
\text { Coefficients }^{\mathrm{a}}
$$

\begin{tabular}{|c|c|c|c|c|c|}
\hline \multirow[b]{3}{*}{ Model } & \multirow{2}{*}{\multicolumn{2}{|c|}{$\begin{array}{l}\text { Unstandardized } \\
\text { Coefficients }\end{array}$}} & \multirow{3}{*}{$\begin{array}{c}\text { Standardized } \\
\text { Coefficients } \\
\text { Beta }\end{array}$} & \multirow[b]{3}{*}{$\mathrm{t}$} & \multirow[b]{3}{*}{ Sig. } \\
\hline & & & & & \\
\hline & B & Std. Error & & & \\
\hline 1 (Constant) & 13.247 & 2.455 & & 5.395 & .000 \\
\hline Disiplin (X) & .672 & .064 & .785 & 10.456 & 000 \\
\hline
\end{tabular}

Berdasarkan hasil pengujian pada tabel di atas, diperoleh persamaan regresi $\mathrm{Y}$ $=13,247+0,672 X$. Dari persamaan tersebut dijelaskan sebagai berikut:

1) Konstanta sebesar 13,247 diartikan jika disiplin tidak ada, maka telah terdapat nilai produktivitas karyawan sebesar 13,247 point.

2) Koefisien regresi disiplin sebesar 0,672, angka ini positif artinya setiap ada peningkatan disiplin sebesar 0,672 point maka produktivitas karyawan juga akan mengalami peningkatan sebesar 0,672 point.

\section{b. Analisis Koefisien Korelasi}

Analisis koefisien korelasi dimaksudkan untuk mengetahui tingkat kekuatan hubungan dari variabel independen terhadap variabel dependen. Adapun hasil pengujian sebagai berikut: 
Tabel 3. Hasil Pengujian Koefisien Korelasi Disiplin Terhadap Produktivitas Karyawan.

Correlations $^{\mathrm{b}}$

\begin{tabular}{llr|r} 
& & & Produktivitas Karyawan \\
& & Disiplin $(\mathrm{X} 1)$ & \multicolumn{2}{c}{ (Y) } \\
\hline Disiplin (X) & Pearson Correlation & 1 & $.785^{* *}$ \\
\cline { 2 - 4 } & Sig. (2-tailed) & & .000 \\
\hline $\begin{array}{l}\text { Produktivitas Karyawan } \\
\text { (Y) }\end{array}$ & Pearson Correlation & $.785^{* *}$ & 1 \\
\cline { 2 - 4 } & Sig. (2-tailed) & .000 & \\
\hline
\end{tabular}

Berdasarkan hasil pengujian diperoleh nilai korelasi sebesar 0,785 artinya disiplin memiliki hubungan yang kuat terhadap produktivitas karyawan.

\section{c. Analisis Koefisien Determinasi}

Analisis koefisien determinasi dimaksudkan untuk mengetahui besarnya persentase pengaruh dari variabel independen terhadap variabel dependen. Adapun hasil pengujian sebagai berikut:

Tabel 4. Hasil Pengujian Koefisien Determinasi Disiplin Terhadap Produktivitas Model Summary

\begin{tabular}{|c|c|c|c|c|}
\hline Model & $\mathrm{R}$ & R Square & $\begin{array}{l}\text { Adjusted R } \\
\text { Square }\end{array}$ & $\begin{array}{l}\text { Std. Error of the } \\
\text { Estimate }\end{array}$ \\
\hline 1 & $.785^{\mathrm{a}}$ & .617 & .611 & 2.416 \\
\hline
\end{tabular}

Berdasarkan hasil pengujian diperoleh nilai determinasi sebesar 0,617 artinya disiplin memiliki kontribusi pengaruh sebesar $61,7 \%$ terhadap produktivitas karyawan, sedangkan sisanya sebesar 38,3\% dipengaruhi oleh faktor lain yang tidak dilakukan penelitian.

\section{d. Uji Hipotesis}

Pengujian hipotesis dengan uji t digunakan untuk mengetahui hipotesis mana yang diterima. Rumusan hipotesis: Terdapat pengaruh yang signifikan disiplin terhadap produktivitas karyawan.

Tabel 5. Hasil Uji Hipotesis Disiplin Terhadap Produktivitas Karyawan.

\begin{tabular}{|c|c|c|c|c|c|}
\hline \multirow[b]{3}{*}{ Model } & \multicolumn{4}{|c|}{ Coefficients $^{\mathrm{a}}$} & \multirow[b]{3}{*}{ Sig. } \\
\hline & \multicolumn{2}{|c|}{$\begin{array}{l}\text { Unstandardized } \\
\text { Coefficients }\end{array}$} & \multirow{2}{*}{$\begin{array}{c}\text { Standardized } \\
\text { Coefficients } \\
\text { Beta }\end{array}$} & \multirow[b]{2}{*}{$\mathrm{t}$} & \\
\hline & B & $\begin{array}{c}\text { Std. } \\
\text { Error }\end{array}$ & & & \\
\hline 1 (Constant) & 13.247 & 2.455 & & 5.395 & .000 \\
\hline Disiplin (X) & .672 & .064 & .785 & 10.456 & .000 \\
\hline
\end{tabular}

Berdasarkan hasil pengujian pada tabel di atas, diperoleh nilai t hitung $>\mathrm{t}$ tabel atau $(10,456>1,999)$, dengan demikian hipotesis yang diajukan bahwa terdapat pengaruh yang signifikan atara disiplin terhadap produktivitas karyawan diterima.

\section{PEMBAHASAN HASIL PENELITIAN}

\section{Kondisi Jawaban Responden Variabel Disiplin}

Berdasarkan jawaban responden, variabel disiplin diperoleh ratting score sebesar 3,794 berada di rentang skala 3,40 - 4,19 dengan kriteria baik atau setuju.

\section{Kondisi Jawaban Responden Variabel Produktivitas Karyawan}

Berdasarkan jawaban responden, variabel produktivitas karyawan diperoleh ratting score sebesar 3,874 berada di rentang skala 3,40 - 4,19 dengan kriteria baik atau setuju. 


\section{Pengaruh Disiplin Terhadap Produktivitas Karyawan}

Disiplin berpengaruh signifikan terhadap produktivitas karyawan dengan persamaan regresi $\mathrm{Y}=13,247+0,672 \mathrm{X}$, nilai korelasi sebesar 0,785 atau memiliki hubungan yang kuat dengan kontribusi pengaruh sebesar $61,7 \%$. Pengujian hipotesis diperoleh nilai $t$ hitung $>\mathrm{t}$ tabel atau $(10,456>1,999)$. Dengan demikian hipotesis yang diajukan bahwa terdapat berpengaruh signifikan antara disiplin terhadap produktivitas karyawan diterima.

\section{KESIMPULAN DAN SARAN}

\section{Kesimpulan}

a. Variabel disiplin diperoleh ratting score sebesar 3,794 berada di rentang skala 3,404,19 dengan kriteria baik atau setuju.

b. Variabel produktivitas karyawan diperoleh ratting score sebesar 3,874 berada di rentang skala 3,40 - 4,19 dengan kriteria baik atau setuju.

c. Disiplin berpengaruh signifikan terhadap produktivitas karyawan dengan persamaan regresi $\mathrm{Y}=13,247+0,672 \mathrm{X}$, nilai korelasi sebesar 0,785 atau kuat dan kontribusi pengaruh sebesar $61,7 \%$ sedangkan sisanya sebesar 38,3\% dipengaruhi faktor lain. Uji hipotesis diperoleh nilai $t$ hitung $>t$ tabel atau $(10,456>1,999)$.

\section{Saran}

a. Perusahaan harus menegakkan peraturan dengan baik sesuai dengan ketentuan yang berlaku guna menjamin karyawan diperlakukan dengan adil.

b. Produktivitas perusahaan dapat ditingkatkan dengan memberdayakan karyawan dengan menegakkan peraturan yang baik dan pemberian motivasi yang lebih inten lagi.

\section{VII.DAFTAR PUSTAKA}

Abdullah, M (2014) Manajemen dan Evaluasi Produktivitas Karyawan, Yogyakarta: Penerbit Aswaja Pressindo.

Algifari. (2015). “Analisis Regresi untuk Bisnis dan Ekonomi”. Yogyakarta: BPFE.

Arikunto, Suharsimi (2014). "Prosedur Penelitian Suatu Pendekatan Praktek". Jakarta: Rineka Cipta.

Bangun, Wilson. 2012. "Manajemen Sumber Daya Manusia”. Jakarta: Erlangga

Bejo Siswanto (2013) Manajemen Tenaga Kerja Rancangan dalam Pendayagunaan dan Pengembangan Unsur Tenaga Kerja”, Bandung: Sinar Baru.

Dessler, G. (2006.) Manajemen Sumber Daya Manusia (Jilid II). Jakarta: Indeks. Edi Sutrisno (2016). Manajemen Sumber Daya Manusia. Jakarta: Prenadamedia Group. George Terry R \& Rue, Leslie W. Rue (2016) Dasar-Dasar Manajemen, Jakarta Bumi Aksara.

Gerry Dessler (2016) Human Resources Management, Prenticehall, London: International Inc.

Handoko (2016) Manajemen Personalia dan Sumberdaya Manusia. Yogyakarta: BPFE.

Hasibuan, Malayu S.P. (2016). Manajemen Sumber Daya Manusia. Edisi Revisi. Jakarta: PT Bumi Aksara.

Imam Ghozali (2017). “Aplikasi Analisis Multivariate Dengan Program SPSS”. Edisi Kelima. Semarang: Badan Penerbit Undip.

Istijanto (2014) “Riset Sumber Daya Manusia”. Jakarta: PT. Gramedia Pustaka

Kharis, Ismu Fadli (2011). "Studi Mengenai Impulse Buying dalam Penjualan Online”. 
Semarang : Skripsi Universitas Diponegoro

Luthans Fred (2014) Organizational Behavior, Ney York: McGraw-Hill, New York.

Mangkunegara, Prabu Anwar. (2016). Evaluasi Produktivitas SDM. Cetakan ke tujuh, PT

Refika Aditama: Bandung.

Rao, Purba, (2012). "Measuring Consumer Perceptions Through Factor Analysis”, The Asian.

Robbins, P.S, \& Judge, A.T. (2003). Organizational Behavior. Jakarta: Salemba Empat.

Santoso, Singgih (2015). "Menguasai Statistik Multivariat". Jakarta: PT Elex Media Komputindo.

Sedarmayanti (2016) Manajemen Sumber Daya Manusia, Reformasi Birokrasi dan Manajemen Karyawan Negeri Sipil, Cetakan Kelima, Bandung: PT Refika Aditama. Sudjana (2014) “Metode Statistika”, Bandung: Tarsido.

Sugiyono (2017), "Metode Penelitian Administrasi : dilengkapi dengan Metode $R \&$ D”. Bandung: Alfabeta.

Veithzal Rivai (2015) Manajemen Sumber Daya Manusia Untuk Perusahaan, Jakarta: Raja Grafindo Persada.

Wibowo (2015) Manajemen Produktivitas, Jakarta: PT. Raja Grafindo Persada. 